This item was submitted to Loughborough's Institutional Repository (https://dspace.lboro.ac.uk/) by the author and is made available under the following Creative Commons Licence conditions.

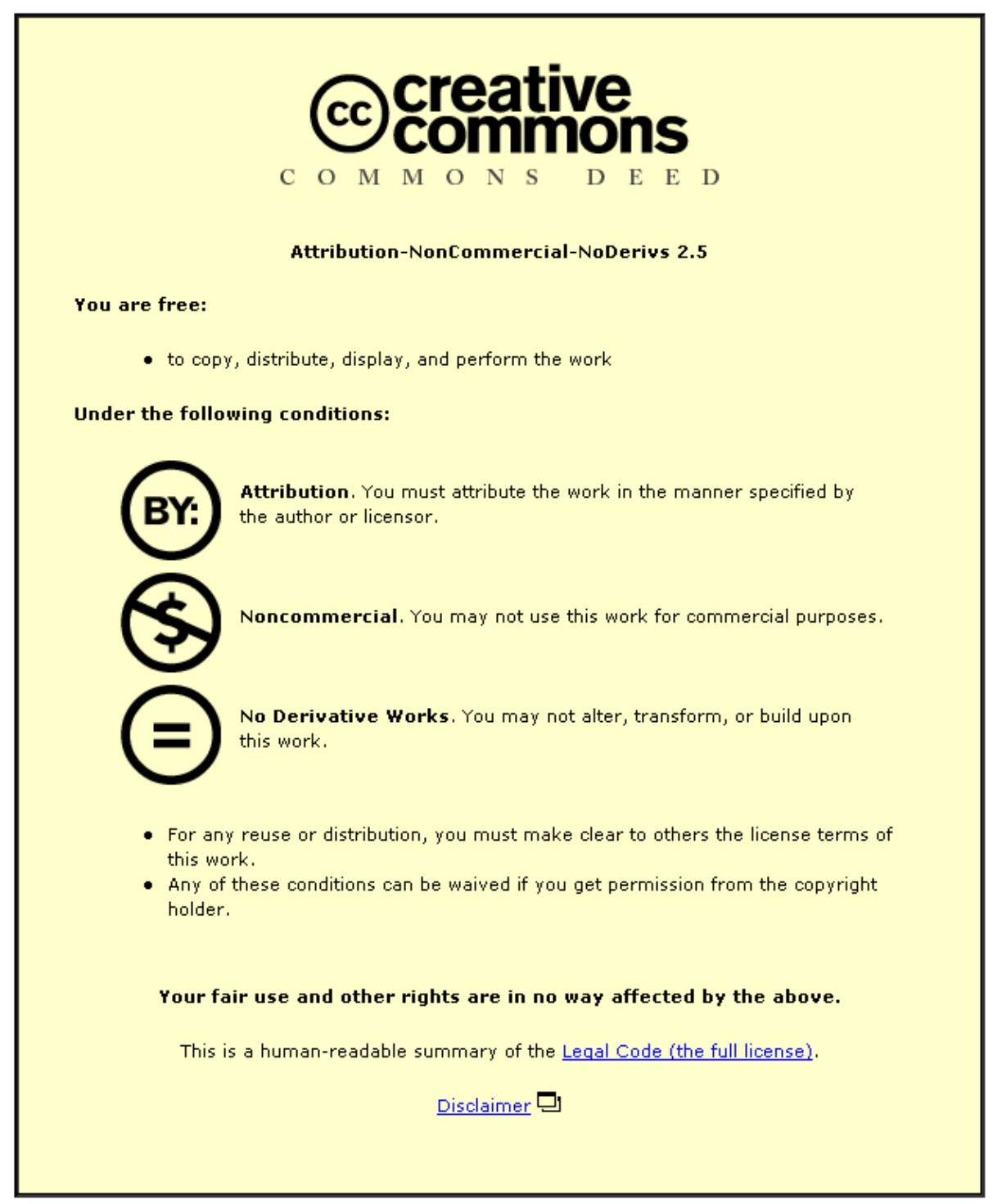

For the full text of this licence, please go to: http://creativecommons.org/licenses/by-nc-nd/2.5/ 


\title{
INFORMAL INTERACTION IN CONSTRUCTION PROGRESS MEETINGS
}

\author{
Abstract \\ The small amount of published research into construction project meetings \\ demonstrates some of the principal difficulties of investigating such sensitive business \\ environments. Using the Bales Interaction Process Analysis (IPA) research method, \\ data on group interaction were collected. A project outcome, namely whether the \\ project was within contract budget, was used as a basis of enquiry between interaction \\ patterns. Analysis was concerned with the socio-emotional (relationship building) and \\ the task-based components of communication and the positive and negative socio- \\ emotional interaction characteristics. Socio-emotional interaction was found to be \\ significantly greater in the projects completed within budget. Socio-emotional \\ interaction is used to express feelings in relation to tasks and it serves as the flux that \\ creates and sustains the group's social framework, which is crucial in a project \\ environment. The data provides an indication of the importance of informal \\ communication in the maintenance of relationships within project meetings.
}

\section{Keywords:}

Interpersonal communication, interaction, meetings, project success

\section{INTRODUCTION}

Informal discussions, either on a one to one basis or in small work groups allows individuals to share knowledge and test ideas in a supportive work environment. In a project environment, face-to-face inter-disciplinary social interaction will usually 
occur in meetings, of various types and formality. Despite the amount of time and energy consumed by meetings they are relatively under-researched (Volkema \& Niederman, 1995; Dainty et al. 2006; Emmitt \& Gorse, 2007). Although there are a number of books written mainly by practitioners with the aim of providing guidance (e.g. Tropman’s Making Meetings Work, 1996), Hartley (1997) concluded that despite their familiarity we do not really know what goes on within this forum.

Meetings are essential mechanisms for information sharing and facilitating decisionmaking. This allows project participants to discuss issues and agree on the most appropriate action. Value is added when the project's social framework supports open interaction and candid discussion. Open exchange offers the best potential for making informed decisions. Although a variety of metrics could be used to measure the efficacy of meetings the main concern for managers should be with the process (effectiveness of group communication), the product (quality of the outcome/solution) and perception (how did the participants perceive the process and the product?).

Construction progress meetings are held on a regular basis throughout the construction period, a forum for all parties to meet and review the progress of the project. It has been argued that construction progress meetings are little more than a ritual, with participants acting out a series of roles (Kreiner 1976). More recent research by Gorse (2002) and Gorse and Emmitt (2007) has helped to illustrate some of the more subtle complexities of interaction within meetings; a combination of formal roles and structures, interspersed with informal episodes of communication have been identified. From a management perspective it could be insightful to gather data from live construction project meetings in an attempt to see how interaction within 
meetings influences the performance of the project. Thus, the aim of the research was to gather data from a series of construction progress meetings across a number of projects using a robust research method, Bales Interaction Process Analysis (IPA), to explore the nature of interaction within meetings and its relationship to the performance of the project. Data collected from the meetings was analysed and then compared with project performance outcomes to identify significant group interaction differences between projects. By using the Bales IPA the focus was on task-based interaction and socio-emotional interaction between the meeting participants, i.e. it was concerned with inter-personal communication.

\section{GROUP AND GROUP MEETING DYNAMICS}

Interpersonal interaction within meetings is full of positive and negative emotion that takes parties through project and social tasks (Gorse 2002). Some members are comfortable with the group and meeting environment; they listen-and interact. Conversely, some participants can be blocked, intimidated and be unduly influenced by the more dominant contributors. Membership of a group can be a satisfying experience; however, some participants can invoke fear, generate a group environment that is tense or fosters boredom, which can make people dissatisfied and annoyed. As a result of their previous experience, some people are reluctant to take part or engage in group interaction (McCroskey 1997).

There are a number of obvious features of group interaction that affect the exchange of information within meetings. For example, with the exception of talking over another member, only one person can speak at a time. Turn-taking within groups 
affects individual contribution; as groups increase in size the average contribution of the individual reduces (Hackman and Vidmar 1970). The ability of an individual to interact is affected by the behaviour of the other members. Generally, group interaction, almost regardless of size is dominated by two or three members (Napier and Gershenfeld 1989; Gorse 2002). When making group decisions, the effectiveness of the decisions are in some way proportionate to the individual's contribution, the relevant knowledge that individual members can obtain from the group and the ability of both the individual and the group to recognise and respond to the information (Emmitt and Gorse 2003). Meeting invitations and agendas are structured to decide who attends the meeting and hence this does influence the topics covered, although formal rules are rarely used to govern an individual's contribution to the meeting. And, although a meeting's purpose may be classed as formal, it is the implicit, possibly, practiced and learned interpersonal behaviour and impromptu acts that represent much of the meeting's interpersonal structure.

Indeed, some members adopt interaction behaviours that enable them to interrupt, gain the floor, hold others attention and make their point, while others make minimal contributions-(Gorse and Sanderson 2006). Bell (2001) and Gorse’s (2002) study of workgroups found that group interaction is unevenly skewed and some members play a minimal role, being reluctant to participate, while others dominate interaction. Depending on the nature of the task, skewed interaction can adversely affect the group productivity, especially when those with relevant knowledge are blocked or suppressed. 
Recipients often adjust their socio-emotional behaviour to suit communication (Gorse 2002). Thus, different emotional emphasis is used to gain influence and deliver project information. The context in which the emotion is used, an individual's knowledge and experience will affect the interaction behaviour and response (Goleman 1996; LeDoux 1998).

Those who dominate may not be aware that their contributions suppress others. Video recording of groups and self-observation in training events has been used to enable individuals to recognise how their behaviour affects others (Gorse and Whitehead 2002). However, it is not always possible to collect communication data from real business environments using video recorders or audio tape recorders. Research conducted by Hugill (1999; 2000; 2001) made use of a tape recorder in a real business environment and, although occasionally, those present in the meeting did ask for the recorder to be switched off during conversations that were considered sensitive, the detail of data collected was very rich. In Hugill's work the richness of the data and the detail of enquiry meant that only one hour of interaction from one meeting was analysed. Clearly the purpose of the study will influence the type of data that can be collected and observations that can be made.

\section{METHODOLOGICAL ISSUES}

While interpretive and ethnographic observation offers insight into specific episodes of meetings, such methods can also be restrictive. As already noted, Hugill (2001) extracted and explored the detail of a group's interaction using ethnomethodology, but the investigation was limited to analysis of just 1 hour of a meeting's interaction. The level of detail of the enquiry and the time and resources involved prevented analysis 
of the other meetings observed. Equally, the more positivist approach uses predefined labels which serve to restrict observations to those categories that are described. Both the very detailed interpretive and more quantitative positivist approaches, which restrict data collection to codes but capture extended sets of data, lend themselves to interpretive and statistical analysis and have their role to play in furthering our understanding of interaction within meetings.

Different perspectives and methods of enquiry can help to explore and understand the dynamics of the meeting. Most positivist research in group communication has emerged from an interpretive study that recognised and labelled behaviours. Particular emphasis in this study has been placed on task and emotional behaviour and the previously uncharted patterns that manifest over a number of meetings. Identifying aspects of communication in the meeting that are not formally defined or structured is important to understanding the nature of the meeting. An examination of the interplay between task and socio-emotional interaction will help to understand part of the informal meeting structure.

\section{Researching task and socio-emotional interaction}

Ever since observations of interaction were first recorded scholars have recognised the importance of task and emotional interaction within the group setting; a situation that is still valid today. (McLeod and Kettner-Polley 2004). The two dimensions are considered to be essential components in the management of interpersonal relationships and the accomplishment of tasks. For the group to exist the members engage in relational communication (socio-emotional) maintaining the forum and, to 
achieve outcomes, groups use task-based discussion to work through group goals (Bales 1970).

Although there are a number of research methods used for recording group communication the Bales Interaction Process Analysis (IPA) method continues to provide a robust method with a very distinct focus on the socio-emotional and taskbased components. Bales IPA is versatile and robust and, although other methods claim to offer features that collect additional data, the longevity of use has resulted in a considerable body of information, which has steadily developed understanding of group interaction in various contexts (Tuckman1965; Belbin 1981; 1993; Armstrong and Priola 2001; Chou 2002; Fahy 2006).

Recently there has been a decline in external (researcher) observation with those investigating using self-perceptions and observations from participants within the group. The two main reasons for this shift are that direct observation is both expensive and time consuming. While interpersonal ratings from participants alone provide perceptions about biases and motivation, what can be lost is the detailed forensic analysis of group interaction that is only possible with direct observation (McLeod and Kettner-Polley 2004). Some research projects which have used interpersonal ratings to delve into members beliefs also supported their analysis with the Bales IPA direct observation, for example, Armstrong and Priola (2001) Priola, Smith and Armstrong (2004); however, in 'real world' research projects that require meeting members to complete questionnaires, the response rates suffer. 
Although time consuming, direct observation places no resource implications on those being observed; indeed, it is desirable for those being observed to carry on as normal and not do anything different. Contrary to this is self-analysis which can be quite demanding on the participants. The Bales SYMLOG system, which is based on interpersonal ratings, can take the participants 3-4 hours to understand and complete (Bales 1980). When attempting to use a similar system Emmitt and Gorse (2007) failed to obtain valid interpersonal ratings and reflections from professionals. Work demands and lack of interest meant that feedback sheets required from the professionals were given a very low priority. The quality and content of the data provided was so inconsistent that follow up telephone calls were necessary. While the two methods helped to validate a few findings, it was soon revealed that the professionals had provided so little written information that the data collected on questionnaires was incomplete and not useful.

Direct observation using the Bales IPA method, which places minimal demands on the participants is an effective way of collecting interaction data from professional groups and is still as useful as it was in the 1950's when it was first introduced. The research method, which has stood the test of time, has systematically developed understanding. The longevity of use coupled with ability of the tool to collect data with minimal involvement from those being researched makes it well suited to study of meetings in the construction environment.

\section{IPA and construction research}

The Bales IPA has been used extensively to examine group interaction in fields other than construction. This includes Bales' $(1950,1953,1958,1970)$ profiles of social and 
student groups; Cline’s (1994) study of disagreement and agreement; Landsberger’s (1955) records of mediation meetings; Bell’s (2001) observations of multidiscipline child protection teams and Fahy (2006) comparison of face to face and online groups. In construction a small number of researchers have successfully applied Bales IPA, namely Wallace (1987), Gameson (1992), Gorse (2002), Gorse et al. (2006 a,b) Bellamy et al (2005) and Emmitt and Gorse (2007) providing some insights into communication behaviour in construction.

\section{RESEARCH METHOD}

Data were collected over a series of construction progress team meetings from ten construction projects in the West Yorkshire area of the UK. The projects varied in size and complexity, although they were drawn from the same geographical location. Membership of the meeting included architects, client's representatives and consultants, contractor's representatives, key subcontractors, structural engineers and mechanical and electrical engineers. Although the number of participants varied between projects, typically each meeting involved 7-9 participants. Meetings were held fortnightly in the contractor's site accommodation offices to monitor progress and to address management and design issues relating to the project. Three meetings were observed for each project, which provided data from a total of 30 progress meetings. Observations were recorded, by one researcher, using the Bales Interaction Analysis Process (IPA) technique, which identifies the communicator and the target of communication (recipient). In a group situation, the direction of communication could be aimed at the whole group or more specifically, and overtly, directed at an individual. The overt direction of communication was recorded. 
Using the IPA system, classification of statements falls into either one of six 'task related categories' (category descriptions 4 -9) or six 'socio-emotional categories' (category descriptions 1-3 and 10-12), (see Table 1). The data were recorded using a prepared check-sheet with tick-boxes enabling the identification of the person speaking, recipient, and the interaction category. The observer sat at the meeting table but took no active role in the meeting. The participants were aware of the observation. A brief qualitative note was made of the issue being discussed. When overt changes in the socio-emotional behaviour of the group occurred qualitative notes were made during, and immediately after, the meeting. While Bales’ IPA serves to identify the socio-emotional and task based categories used by each member of the group and the shift in categories, at the pilot study stage of the research it was found useful to place a link to the agenda items discussed in the task categories and to note the nature of emotional exchanges as the socio-emotional interactions occurred. To ensure that the data collection using the Bales IPA (quantitative method) remained consistent and hence reliable, it was only possible to make very brief notes during the meeting. Following the meeting further notes were made, providing additional explanation of the interaction events that had occurred. The qualitative notes were useful in helping to understand how the task-based and socio-emotional interaction was used, equally it offers insight into the reality of the meeting that would otherwise be missed. Without the use of video or audio, which, as already discussed, can be restrictive, such methods offer useful insights. Using immediate recall to supplement observations has been used by Loosemore (1996) and Emmitt (1997) and while some variance due to particular focus of memory is inevitable the insight provides important information about influences and background to the interaction. 
[Insert Table 1]

\section{RESULTS}

Use of the Bales IPA method resulted in a large body of quantitative data, supported by the qualitative notes. The work reported below draws on the analysis of both sets of data and focuses on the informal aspects of the interaction.

As with previous studies, interaction within the group was skewed with one or two individuals dominating the interaction. The level of interaction did vary depending on the specific topic being discussed, with individuals contributing more when specific issues relating to their area of work arose. However, typically, one or two members were more vocal, led and participated more in the meetings compared to the other members.

Typical of all other group research that has used the Bales IPA, the management and design teams used more task-based than socio-emotional interaction. Task-based interaction is that used to obtain and explore information, to question and guide the group through its tasks and activities. Although some would argue that all interaction contains a level of emotion (McLeod and Kettner-Polley 2004), task-based interaction is the lowest level of emotion, with no overt emotion that could be seen to influence or affect relationships. Socio-emotional interaction represents the interaction used to build, develop and maintain relationships and that used to engage in and recover from conflict. Negative emotional interaction, such as disagreements, expressions of frustration and conflict serves as a potential threat to relationships. Thus, the balance between negative and positive socio-emotional interaction is important to show an 
individual's emotional position within the context of discussion. Positive socioemotional interaction is also important to maintain relationships. Socio-emotional interaction is often termed relationship communication, the acts help to engage, strengthen, threaten and withdraw from relationships. The level of socio-emotional interaction observed was very low when compared with previous studies of social groups.

In more formal environments such as workgroups, the informality associated with socio-emotional interaction often suffers. Task-based interaction such as asking questions and giving information is usually based on the facts and history of the project, while socio-emotional interaction attempts to exert some influence that has a greater affect on relationships and the group’s social structure. Positive socioemotional interactions are often seen as relationship building and repairing, while negative socio-emotional interactions questions and threatens relationships. Conversations that inadvertently build or threaten relationships co-exist with the informal aspect of the meeting. Very informal discussions that took place prior to and at breaks in the meeting, which used topics such as golf, football, the weather, parking and recent news were all populated with positive socio-emotional interaction, exchanging information and more importantly socio-emotional signals that express relational commitment. Such acts all fall within the positive Bales socio-emotional categories 1, 2 and 3. In projects completed both within budget and over budget, the use of such categories was small (Table 2) but was greater in projects completed within budget. Occasional negative socio-emotional responses quickly indicated a reluctance to commit to such conversations, exchanging signals about the type of conversations and relationships that were possible. It is interesting that negative 
socio-emotional interaction (categories 10, 11 and 12) is also greater within projects that were completed within budget. The emergent interaction patterns form the group’s socio-emotional framework within which group decisions will be made.

\section{Quantitative overview}

A forensic examination of task-based interaction showed that the use of task-based interaction, including information, opinion and direction giving, was consistently higher than that of requesting task-based information, opinion and suggestion. The positive socio-emotional interaction is also consistently higher than the negative socio-emotional communication.

The construction sector has often been described as adversarial, prone to dispute (e.g. Latham 1994; Pickavance 2005) and can be an environment filled with negative emotion (Wallace 1987), yet this was not evident in the data. Occasional outbursts were observed; however, they were relatively isolated to projects and between certain individuals. Although it cannot be said that this model is representative of all construction site meetings, the model was drawn from meetings which captured 15077 communication acts. Using Pearson Chi-square test a significant difference was found between projects within and over budget (Table 2). Although the differences found were small, the overt socio-emotional behaviour observed had a notable effect on group interaction. Qualitative observations were important in helping to identify the nature of the interaction during task-based and socio-emotional exchanges.

[Insert table 2] 


\section{DISCUSSION}

When comparing the results with previous studies the analysis shows considerable differences between the construction based studies and the interaction norms as depicted by Bales (1970). The construction based observations show very low use of socio-emotional acts when compared to Bales 'normal' range. Results from previous studies that have investigated construction professionals’ interaction, such as Wallace (1987) and Gameson’s (1992), have also found low levels of emotional expression. Much of Bales original work used to produce the 'normal' range was based on social groups rather than work groups. The few studies that have investigated work groups show much lower uses of socio-emotional communication than that found in other contexts (Wallace 1987; Gameson 1992; Bell 2001; Bellamy et al. 2005). Early studies by Bales (1970) found that groups which used a low amount of socioemotional interaction were often in the early stages of group development.

Bales found that as groups develop, and become more familiar with each other, their behaviour changes. Initially, members use task-based communication to help them to tentatively gathering information on the other group members' beliefs and attitudes. Once group members have become familiar with others socio-emotional interaction is used to put forward harder positions, more factual and non-emotive issues are discussed. Early exchanges are important for each member to learn about the personal behaviours and characteristics of others. In a project environment where participants often find themselves in new groups, i.e. working with others for the first time, the socio-emotional interaction is crucial for developing working relationships. Informal interaction that took place prior to, and during, breaks in the meeting are also seen to be important in this situation. Even where parties do not break into conversations their 
mannerisms, such as, formal or informal gestures as they arrive at the meeting, result in the exchange of positive or negative socio-emotional exchanges. Smiles, nods and brief greetings show an openness to potential conversation and relationships, whereas formal mannerisms, non-descript facial expressions or stern looks clearly indicate a reluctance to socio-emotional exchanges, resulting in a greater degree of formality.

Socio-emotional exchanges that emerge during the meeting are influential and therefore important for the overall performance of the project. As individuals become more aware of personalities and the developing social context of the group and project environment they may openly engage in the group and commit to relationships. As the social framework develops over time the group members attempt to understand other members’ motives. How members react to different messages provides valuable information on how potential relationships are likely to develop. Socio-emotional reactions offer clues to behaviour that would be considered acceptable and unacceptable. It is at this point that informal interaction can emerge as members know what is, and what is not, acceptable to others. As each member engages in social interaction the group’s structure develops and the framework in which interaction takes place emerges (Bales 1970). The informal positive emotional exchanges regarding the weather, parking and sport that took place prior to the meeting provide a mechanism for understanding individual characteristics and interpersonal relationships. Equally, the negative or more formal responses also provide the same information. Since the socio-emotional exchanges take place both prior to and during the meeting the group is said to develop. 
Groups that reach the later stages of group development show an increased use of socio-emotional, informal, communication (Heinicke and Bales 1953; Bales 1970). Developed groups are said to have established their behaviour norms with individual members being more confident to express socio-emotional acts in order to manage relationships and work through the group tasks. Greater amounts of laughing and joking occur and the relationships are sufficiently established to express and deal with greater negative emotion. Socio-emotional interaction that moves away from any perceived agenda may be considered informal. Developed groups also use a broader range of communication acts and the potential for informality is at its greatest. It is at this stage that the work groups seem to differ from that of the social groups. The level of positive and negative socio-emotional interaction in work groups is very low in comparison with the social group. Interaction could be stifled because the members do not have sufficiently strong relationships or because of the formality of the business environment, which restricts informal interaction and social engagement. Nevertheless, socio-emotional interaction is very limited. While relatively small, the amount of socio-emotional behaviour was still found to have a notable affect on group behaviour.

Even when emotional outbursts occurred the behaviour of the group would not be described as uncontrolled. Bales (1970) and Socha and Socha (1994) provide examples of uninhibited and uncontrolled behaviour in their studies of juveniles. Juveniles lack interaction control and their behaviour is characterised by outbursts of emotion. As people mature their behaviour becomes more restrained (Socha and Socha 1994). Clearly the behaviour of the work groups, including that of the progress meetings, are not overly emotionally expressive. Indeed the discussion is 
predominantly task-based as members attempt to express, understand and solve problems. As in adult groups observed by Bales (1950;1970), information and suggestions are often supported by explanation; generally, communication is structured, controlled and restrained. Adults do not normally express high levels of extreme emotional behaviour. While the behaviour of construction professionals may be different to other groups, and not within the Bales normal range for adult groups, it does not resemble the uncontrolled behaviour of juveniles (Gorse and Emmitt 2007).

The few studies that have looked at work groups (Landsberger 1955; Gameson 1992; Bell 2001) provide initial evidence that the working and commercial environment reduces emotional communication to a lower level compared with other studies. (Bellamy et al. 2005; Fahy 2006). The formality of the meeting and the nature of projects, which do not have longevity, possibly influence the level of informality and socio-emotional behaviour that can emerge.

In the progress meetings observed, the exchange of socio-emotional interaction, although responsible for only a small proportion of the total interaction, had a notable change in the group dynamic. As the majority of interaction was task-based any socioemotional intervention was noticeable and changed the interaction within the group. The group became quiet and members focused on the person expressing their view. When negative emotional exchanges occurred the group became very attentive. If arguments emerged some members appeared anxious. Occasionally members appeared frustrated and expressed their dissatisfaction. While such emotion changed the atmosphere none of the members offered to help the individual. Conversely where members identified a problem, showed concern and specifically addressed the issue 
with an individual it often resulted in an agreed course of action. Interestingly, while both frustration and specifically addressing concerns were expressed by use of negative socio-emotional interaction, the interaction directed at an individual achieved greater response than that which was just expressed to the group. Quantitative results showed that negative emotion was often followed by positive emotion and slightly more so in the successful groups, this was also supported by the qualitative observations. When positive emotion was used the mood of the meeting became more relaxed and friendly. Friendliness was observed in the form of smiles, encouragement, supporting statements and jokes. Further investigation is required to investigate links between informal exchanges prior to the meeting and the ability of individuals to express positive and negative expression during the meeting. Some observations were made during informal episodes.

All gestures that could not be tied to the agenda or associated with tasks or business were considered informal. The formal agenda of a meeting is interspersed with pockets of emotional expression that help arrive at decisions. Even though socioemotional interaction in construction groups is minimal it has an important role to play in the management of discussions. The informal conversations supported by positive socio-emotional exchanges that are exchanged following disagreement and conflict are important in the repair and maintenance of the relationships. Informal conversations attempt to re-engage and rebuild relationships, avoiding the sensitive subject matter that had previously manifest as a negative socio-emotional exchange. Separating subject matter may offer a way of repairing and rebuilding before returning to sensitive issues, and warrants further investigation. Occasionally, following negative socio-emotional interaction a member would joke or make a positive socio- 
emotional gesture. Observations and change in quantitative patterns suggested that the informal positive emotional interjection served to break up the negative socioemotional exchanges. Previous research suggests that such changes are necessary to maintain relationships.

The significant, but minimal, level of emotional interaction plays an important part in group communication. A broad range of communication acts were observed. Quantitatively, the research showed that greater use of positive and negative socioemotional interaction was significantly higher in projects with positive outcomes (the positive outcomes investigated for the purpose of this project were: those completed within the contract period, within budget and without formal actions towards litigation). However, further investigation is necessary to uncover the nuances of socio-emotional exchanges and their affect on members and group outcomes. Figure 1 provides a model of the differences found between projects with positive and negative outcomes. While the work is not conclusive, it provides important data relating to the interplay between task and socio-emotional communication. The qualitative observations highlight the nature of such interactions and provide some insight into how members of the temporary project organisation influence decision making through, what may be described as, informal socio-emotional interaction.

[Insert Figure 1]

\section{CONCLUSION}

Emphasis was on the interaction of professionals attending construction progress meetings, essentially a rare insight into the informality of face-to-face interaction 
within a formal project setting. Analysis of data indicated that the informal interaction was important in developing relationships and appeared to influence the success of the groups and their ability to manage project outcomes. Based on these findings it would seem reasonable to suggest that further investigation is required into the area of informal interaction within live construction projects.

Use of negative and positive socio-emotional interaction within the site meetings and its use to influence behaviour is clearly important, yet this is the only study that has focused on this topic in the context of live construction projects. The adversarial behaviour widely reported in construction may be a result of failing to use socioemotional interaction to engage in conflict, recover and build and sustain relationships. Thus we could infer that adversarial behaviour is to be expected in projects because it is an important characteristic of group development. Lack of positive and negative socio-emotional interaction may be leading to latent tension that can threaten relationships. Parties must manage both the relationships and the tasks. Within the time constraints of a construction project it is important that professionals have the appropriate communication skills so that issues and problems are properly and rigorously discussed. The nature of the interaction observed tends to suggest that communication skills are not sufficiently developed, nor used to properly engage with other actors. Again, an area worthy of further investigation. The episodes of informal conversation both before and during the meeting were heavy in positive socioemotional content. Previous research has indicated a strong link with such exchanges and the strength of relationships. 
Further research in this area is necessary to determine the extent that such exchanges influence the strength of the relationships and the ability of the parties to deal with the more challenging issues associated with projects.

Group interaction is synonymous with construction, yet the limited amount of research undertaken may be acting as a barrier to the development of good education and training. Equipping professionals with the skills to interact in a socio-emotional environment so that they can exert the necessary influence to complete tasks is essential for project success. Although it is often argued that the links from individual episodes and events within construction are only tenuously linked to the realisation of the project, they are clearly part of the process and warrant investigation to develop better understanding. From this is may be possible to design and apply appropriate education and training programmes to help professionals develop the appropriate knowledge and skills to be effective in a meeting environment.

\section{REFERENCES}

Armstrong, S. J. and Priola, V. (2001) Individual differences in cognitive style and their effects on task and social orientations of self-managed work teams. Small Group Research, 32 (3) June 2001, 283-312

Bales, R.F. (1950) Interaction process analysis: A Method for the study of small groups, Addison-Wesley Press, Cambridge USA

Bales, R.F. (1953) The equilibrium problem in small groups. In: T. Parsons, R.F. Bales and E.A. Snils (Eds.) Working papers in the theory of action. Free Press. New York. 111163 
Bales, R. F. (1958) Task roles and social roles in problem-solving groups. In: E.E. Maccoby, T. M. Newcomb, E.L. Hartley (Eds.) Readings in Social Psychology, $3^{\text {rd }}$ Ed. Holt, New York. 437-447

Bales, R.F. (1970) Personality and interpersonal behaviour, Holt, Rinehart and Winston. New York.

Bales, R.F. (1980) SYMLOG case study kit: With instructions for a group self study. New York, The Free Press.

Belbin, R. M. (1981) Management Teams, Why They Succeed of Fail, London, Heinemann.

Belbin, R. M. (1993) Team Roles at Work. Oxford, Butterworth-Heinemann.

Bell, L. (2001) Patterns of interaction in multidisciplinary child protection teams in New Jersey, Child Abuse and Neglect, 25, 65-80

Bellamy, T. Williams, A. Sher, W. Sherratt, S and Gameson, R. (2005) Design communication: Issues confronting both co-located and virtual teams. In Khosrowshahi, F. Proceedings of the $21^{\text {st }}$ Conference of the Association of researchers in construction management, SOAS, London. September 7-9 ${ }^{\text {th }}, 353-361$

Dainty, A. Moore, D. and Murray, M. (2006) Communication in Construction: Theory and practice, London, Taylor and Francis

Chou, C. (2002) A comparative content analysis of student interaction in synchronous and asynchronous learning networks. In: the $35^{\text {th }}$ Hawaii International Conference on System Sciences, Jan 1-7 ${ }^{\text {th }}$ Hawaii, 1-9.

Emmitt, S. (1997) The diffusion of innovations in the Building Industry. $\mathrm{PhD}$ thesis, Faculty of Arts, University of Manchester.

Emmitt, S. and Gorse, C. A. (2003) Construction Communication, Blackwell Publishing, Oxford.

Emmitt, S. and Gorse, C. A. (2007) Communication in Construction Teams, London, Spons. 
Fahy, P.J. (2006) Online and Face-to-Face Group Interaction Processes Compared Using Bales’ Interaction Process Analysis (IPA) European Journal of Open, Distance and E-Learning. (2006/i) [accessed from www.eurodl.org]

Gameson, R.N. (1992) An investigation into the interaction between potential building clients and construction professionals, $\mathrm{PhD}$ thesis, University of Reading.

Goleman, D (1996) Emotional intelligence. Bloomsbury, London.

Gorse, C. A. (2002) Effective interpersonal communication and group interaction during construction management and design team meetings, $\mathrm{PhD}$ thesis. University of Leicester.

Gorse, C. A. and Emmitt, S (2007) Communication behaviour during management and design team meetings: A comparison of group interaction. Construction Management and Economics, 25 (11), 1195 - 1211

Gorse, C. McKinney, I. Shepherd, A. Morley, D. and D. Ellis, R. (2006 a) Internal support mechanisms in groups and teams, Proceedings of the Association of Researchers in Construction Management. 22nd Annual Conference, 4th - 6th September, University of Central England. ARCOM. 925 - 934

Gorse, C., McKinney, I. Shepherd, A. and Whitehead, P. (2006 b) Meetings: Factors that affect group interaction and performance. Proceedings of the Association of Researchers in Construction Management. 22nd Annual Conference, 4th - 6th September, University of Central England. ARCOM. 915 - 924

Gorse, C. A. and Sanderson, A. M. (2007) Exploring Group work dynamics. Proceedings of the Association of Researchers in Construction Management. $22^{\text {nd }}$ Annual Conference, $3^{\text {rd }}-5^{\text {th }}$ September, Belfast, . ARCOM University of Reading. pp 295 304 
Gorse, C. A. and Whitehead, P. (2002) The teaching, learning, experiencing and reflecting on the decision-making process. Khosrowshahi, F (Ed.) DMinUCE The 3rd International Conference on Decision Making in Urban and Civil Engineering - London 6th - 8th November '2002 (CDRom)

Hackman, J. R. and Vidmar, N. (1970) Effects of size and task on group and member reactions. Sociometry, 33, 1 (March), 37-54

Heinicke, C. and Bales, R.F. (1953) Developmental trends in the structure of small groups, Sociometry, 16, 7-38.

Hugill, D. (1999) Negotiating access: Presenting a credible project. In: W. Hughes (Ed), Proceedings $15^{\text {th }}$, Annual ARCOM Conference, Liverpool John Moores University, September $15^{\text {th }}-17^{\text {th }} .53-63$.

Hugill, D. (2000) Management as an accomplishment of project team meetings in construction. In: A. Akintoye (Ed.). Proceedings $16^{\text {th }}$, Annual ARCOM Conference, Glasgow Caledonian University, September $6^{\text {th }}-8^{\text {th }} .755-762$.

Hugill, D. (2001) An examination of project management team meetings in railway construction. PhD Thesis. Faculty of Economics, Social Studies and Law, University of Manchester.

Kreiner, K. (1976) The Site Organisation: a study of social relationships on construction sites, $\mathrm{PhD}$ thesis, Technical University of Denmark.

Landsberger, H. (1955) Interaction process analysis of professional behaviour: A Study of labour mediators in 12 labour-management disputes, American Sociological Review, 20, 566-575.

Latham, M. (1994) Construction the Team. London: HMSO

Littlepage, G.E. and Silbiger, H. (1992) Recognition of expertise in decision-making groups: Effects of group size and participation patterns. Small Group Research, 22, 344-355 
LeDoux, J (1998) The emotional brain. Phonix, New York

Loosemore, M. (1996) Crisis management in building projects: A longitudinal investigation of communication behaviour and patterns within a grounded framework. PhD thesis, Department of Construction Management and Engineering, University of Reading.

McCroskey, J. C (1997) Willingness to communication, communication apprehension, and self-perceived communication competence: conceptualizations and perspectives. In: J.A. Daly, J.C. McCroskey, J. Ayres, T. Hopf, D.M. Ayres. Avoiding communication: Shyness reticence, and communication apprehension, New Jersey, Hampton Press. $75-108$

McLeod, P. L. and Kettner-Polley, R. B. (2004) Contributions of psychodynamic theories to understanding small groups. Small group research, 35 (3), 333-361

Napier, R. and Gershenfeld, M. (1989) Groups: Theory and Experience, Dallas, Houghton Mifflin.

Otter den, A. (2005a) Design Team Communication and Performance Using a Project Website, PhD thesis, Eindhoven University Press.

Pickavance, K. (2005) Delay and disruption in Construction Contracts $3{ }^{\text {rd }}$ Ed. London. LLP.

Priola, V. Smith, J.L. and Armstrong, S. J. (2004) Group work and cognitive style: A discursive investigation. Small Group Research. 35 (5) October 2004, 565-595

Socha, T.J. and Socha. D.M. (1994) Children's task-group communication: Did we learn it all in kindergarten? In: Frey. L.R (Ed.) Group communication in context: Studies of natural groups. New Jersey, Lawrence Erlbaum associates. 227-246.

Tropman, J.E. (1996) Making Meetings Work, Sage, Thousand Oaks, CA. 
Tuckman, B. W. (1965) 'Developmental sequence in small groups', Psychological Bulletin, 63, 384-399. The article was reprinted in Group Facilitation: A Research and Applications Journal - Number 3, Spring 2001 and is available $<\underline{\text { http://dennislearningcenter.osu.edu/references/GROUP\%20DEV\%20ARTIC }}$

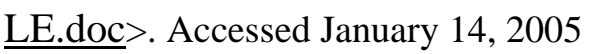

Wallace, W.A. (1987) The influence of design team communication content upon the architectural decision making process in the pre-contract design stages, $\mathrm{PhD}$ Thesis, Department of Building, Heriot-Watt University.

Volkema, R.J. and Niederman, F. (1995) Organizational Meetings. Formats and information requirements. Small Group Research, 26, 3-24. 
Table 1 Bales 12 Interaction categories (Adapted from Bales 1950:9)

\begin{tabular}{|c|c|c|}
\hline 1 & $\begin{array}{l}\text { SHOWS SOLIDARITY - show support, raises others status, gives help, } \\
\text { encourages others, reinforces (rewards) contribution, greets others in a } \\
\text { friendly manner, uses positive social gesture, shows element of kindness. }\end{array}$ & \multirow{3}{*}{$\begin{array}{l}\text { POSITIVE SOCIAL- } \\
\text { EMOTIONAL AREA } \\
\text { Behaviours and gestures used } \\
\text { to engage others in positive } \\
\text { manner, can be used to } \\
\text { encourage commitment, help } \\
\text { build and strengthen } \\
\text { relationships. }\end{array}$} \\
\hline 2 & $\begin{array}{l}\text { SHOWS TENSION RELEASE - jokes (supportively), laughs, shows } \\
\text { satisfaction, relives or attempts to remove tension, offers way out of } \\
\text { problem, expresses enthusiasm, enjoyment, satisfaction }\end{array}$ & \\
\hline 3 & $\begin{array}{l}\text { AGREES - shows passive acceptance, acknowledges other, shows } \\
\text { understanding, complies, co-operates with others, expresses interest and } \\
\text { comprehension. }\end{array}$ & \\
\hline 4 & $\begin{array}{l}\text { GIVES SUGGESTION - makes suggestion, provides direction or } \\
\text { resolution, implying autonomy for others, attempts to control direction or } \\
\text { decision. Makes clear and firm statement. Shows the way forward. }\end{array}$ & \multirow{3}{*}{$\begin{array}{l}\text { TASK AREA: NEUTRAL } \\
\text { Input and attempted } \\
\text { answers. } \\
\text { Acts used to give, exchange } \\
\text { and develop information, } \\
\text { understanding and control. } \\
\text { Provides information and clues } \\
\text { about context, topic, goal and } \\
\text { direction. }\end{array}$} \\
\hline 5 & $\begin{array}{l}\text { GIVES OPINION - offers opinion, evaluation, analysis, express a feeling } \\
\text { or wish. Seeks to analyses, explore, evaluate or enquire. Provides insight } \\
\text { and reasoning, Offers view, without imposing direction on others. }\end{array}$ & \\
\hline 6 & $\begin{array}{l}\text { GIVES ORIENTATION - provides background, further information, } \\
\text { repeats, clarifies or confirms. Brings relevant matters of fact into the forum, } \\
\text { acts that assist group focus on the context rather than the direction. }\end{array}$ & \\
\hline 7 & $\begin{array}{l}\text { ASKS FOR ORIENTATION - asks for further information, repetition or } \\
\text { confirmation. Draws out issues, facts and background information. Acts } \\
\text { used to request relevant information and understand the topic and context. }\end{array}$ & \multirow{3}{*}{$\begin{array}{l}\text { TASK AREA: NEUTRAL } \\
\text { Questions and requests. } \\
\text { Information finding and } \\
\text { question asking. Acts used to } \\
\text { request, seek, draw, search, } \\
\text { withdraw, analyse and explore } \\
\text { information. Also includes } \\
\text { requests for direction }\end{array}$} \\
\hline 8 & $\begin{array}{l}\text { ASKS FOR OPINION -asks others for their opinion, evaluation, analysis } \\
\text { or view. Requests that others express how they feel or state their } \\
\text { preferences. Acts used to request and explore reasoning. }\end{array}$ & \\
\hline 9 & $\begin{array}{l}\text { ASKS FOR SUGGESTION - asks for suggestion, direction, possible ways } \\
\text { of action. Requests for firm contribution, solution or closure to problem. } \\
\text { Asks another member to take on autonomy of others. }\end{array}$ & \\
\hline 10 & $\begin{array}{l}\text { DISAGREES - shows disagreement (without any anger or tension), passive } \\
\text { rejection, expresses position to withhold help, does not support view or } \\
\text { opinion, openly fails to concur with view, rejects a point or suggestion. }\end{array}$ & \multirow{3}{*}{$\begin{array}{l}\text { NEGATIVE SOCIAL- } \\
\text { EMOTIONAL AREA } \\
\text { Negative reactions. Include } \\
\text { non-conformative acts that } \\
\text { show little emotion to outward } \\
\text { aggression. Behaviours used to } \\
\text { disagree, reject information, } \\
\text { question commitment and } \\
\text { threaten relationships. }\end{array}$} \\
\hline 11 & $\begin{array}{l}\text { SHOWS TENSION - shows concern, apprehension, dissatisfaction or } \\
\text { frustration. Persons interacting are tense, on-edge. Disagreement supported } \\
\text { be negative emotion. Act that express sarcasm or are condemning. }\end{array}$ & \\
\hline 12 & $\begin{array}{l}\text { SHOWS ANTAGONISM - acts used to deflates others status, asserts self } \\
\text { on others. Openly suppresses another member, purposely blocks another or } \\
\text { makes a verbal attack, expressions of aggression and anger. }\end{array}$ & \\
\hline
\end{tabular}

Table 2 Comparison of socio-emotional and task based interaction observed on projects within budget and over budget:

\begin{tabular}{|c|c|c|c|c|c|c|}
\hline \multirow[t]{2}{*}{ INTERACTION CATEGORIES } & \multicolumn{2}{|c|}{ Within Budget } & \multicolumn{2}{|c|}{ Over budget } & \multicolumn{2}{|c|}{$\begin{array}{l}\text { Total interaction } \\
\text { observed }\end{array}$} \\
\hline & No. & $\%$ & No. & $\%$ & No & $\%$ \\
\hline Positive socio-emotional interaction & 816 & 8 & 373 & 7 & 1189 & 8 \\
\hline Giving task-based interaction & 7037 & 73 & 4102 & 76 & 11139 & 74 \\
\hline Requesting task-based interaction & 1575 & 16 & 801 & 15 & 2376 & 16 \\
\hline Negative socio-emotional interaction & 259 & 3 & 114 & 2 & 373 & 3 \\
\hline Total interaction observed & 9687 & & 5390 & & 15077 & \\
\hline
\end{tabular}




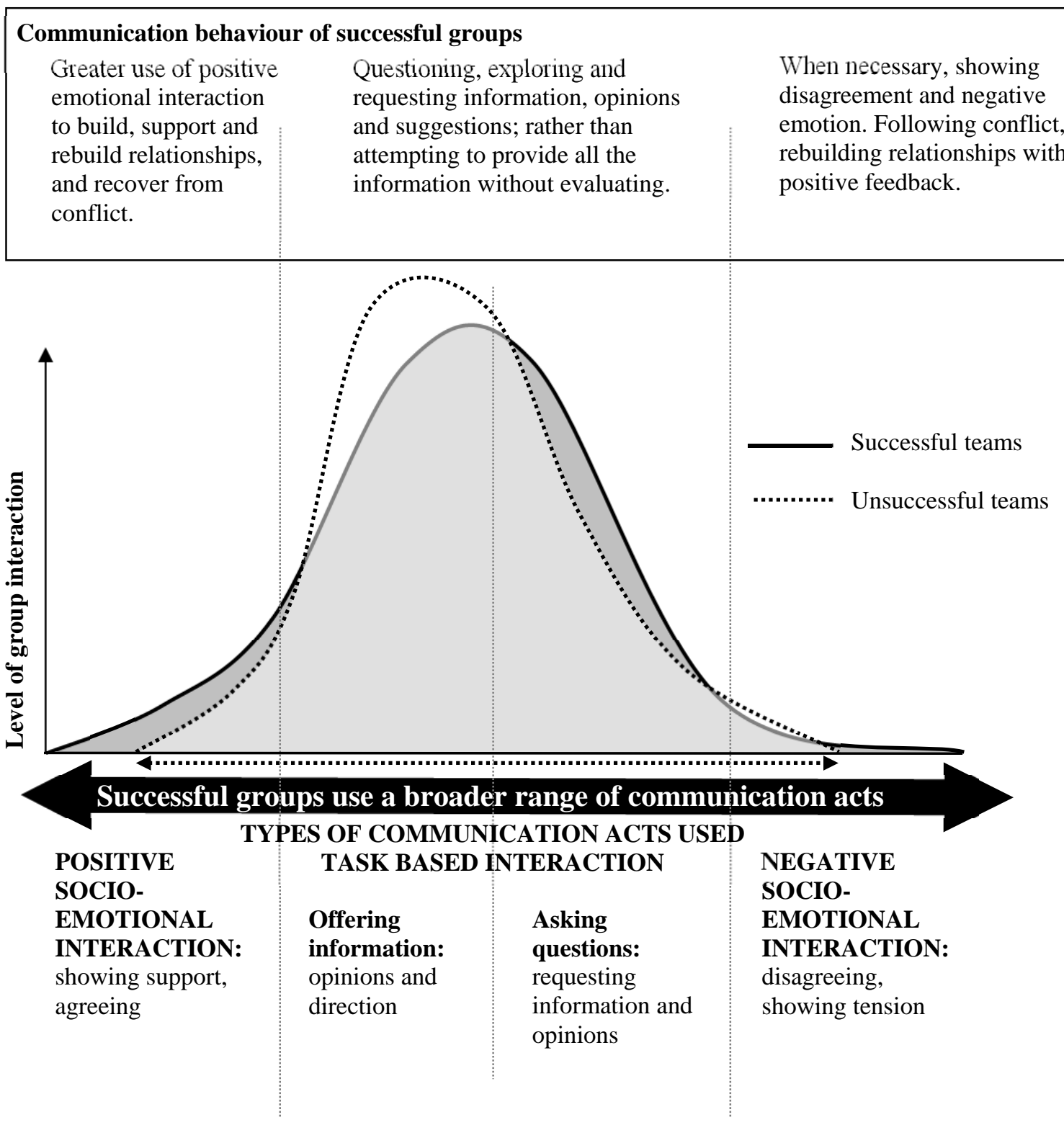

Figure 1. Characteristics of successful and unsuccessful management and design group meetings 